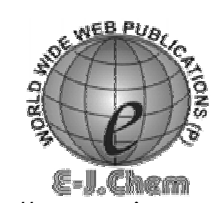

http://www.e-journals.net
ISSN: 0973-4945; CODEN ECJHAO

E-Journal of Chemistry

Vol. 1, No. 1, pp 38-42, March 2004

\title{
High Performace Liquid Chromtographic Determination of Nicardipine Hydrochloride in Human Plasma
}

\author{
Y.S.R. KRISHNAIAH ${ }^{1}$, V. SATYANARAYANA ${ }^{2}$ and P. BHASKAR ${ }^{2 *}$ \\ ${ }^{1}$ Department of Pharmaceutics \\ Faculty of Pharmacy, Kuwait University \\ PO Box 24923, SAFAT 13110, Kuwait \\ ${ }^{2}$ Department of Pharmaceutical Sciences \\ Andhra University, Visakhapatnam-530 003. \\ e-mail: bhas_20@rediffmail.com
}

Received 10 February 2004; Accepted 24 February 2004

\begin{abstract}
A sensitive high-performance liquid chromatographic method was developed for the estimation of nicardipine hydrochloride in human plasma. Varying amount of nicardipine hydrochloride (2.5 to $150 \mathrm{ng} / 0.5 \mathrm{~mL}$ ) and fixed quantity (100 ng/0.5 mL) of nifedipine (internal standard) was added to blank human plasma, and a single step extraction was carried out with ethyl acetate. The mixture was centrifuged, ethyl acetate layer separated, dried and reconstituted with $100 \mu \mathrm{L}$ of acetonitrile. Twenty microliters of this solution was injected into a reverse phase C-18 column using a mobile phase consisting of acetonitrile: $0.02 \mathrm{M}$ potassium dihydrogen phosphate $(\mathrm{pH} 4.0)$ in the ratio of $60: 40 \mathrm{v} / \mathrm{v}$ and the eluents were monitored at $239 \mathrm{~nm}$. The method was validated for its linearity, precision and accuracy. The calibration curve was linear in the range of $5-150 \mathrm{ng} / 0.5 \mathrm{~mL}$ of plasma and the lower detection limit was 2.5 $\mathrm{ng} / 0.5 \mathrm{~mL}$ of plasma. The intra- and inter-day variation was found to be less than $2.5 \%$ indicating that the method is highly precise. The mean recovery of nicardipine hydrochloride from plasma samples was $89.6 \pm 2.60 \%$. The proposed HPLC method was applied for the estimation of nicardipine hydrochloride in human plasma after oral administration of an immediate release nicardipine hydrochloride capsule (dose $30 \mathrm{mg}$ ) to 6 adult male volunteers. There was no interference of either the drug metabolites or other plasma components with the proposed HPLC method for the estimation of nicardipine hydrochloride in human plasma. Due to its simplicity, sensitivity, high precision and accuracy, the proposed HPLC method may be used for biopharmaceutical and pharmacokinetic evaluation of nicardipine hydrochloride and its formulations in humans
\end{abstract}

Keywords: Nicardipine hydrochloride, HPLC, Human plasma, Pharmacokinetic 


\section{Introduction}

Nicardipine hydrochloride, a potent calcium channel antagonist, is used in the treatment of angina pectoris and hypertension ${ }^{1,2}$. The terminal half-life of nicardipine hydrochloride after single oral administration in human subjects varies from 2 to $4 \mathrm{~h}$. After oral administration, nicardipine hydrochloride undergoes extensive first-pass elimination, and inter-and intra-subject variability of plasma concentration is observed ${ }^{2}$. Because of the first- pass elimination, oral bioavailability ${ }^{2}$ of nicardipine hydrochloride in human subjects has been reported to be as low as 30-35\%. Several analytical methods have been reported for the estimation of nicardipine hydrochloride in plasma by HPLC ${ }^{3-11}$, HPLC with gas chromatography-mass spectrometry ${ }^{12}$ and GC-MS combined with chiral stationary phase HPLC ${ }^{13}$. The HPLC methods are simple, sensitive, precise and highly accurate, and require small quantity of sample. But some of the reported HPLC methods $8,10,11$ utilized special columns for the estimation of nicardipine hydrochloride in biological samples. The HPLC with gas chromatography-mass spectrometry ${ }^{12}$ and GC-MS combined with chiral stationary phase HPLC ${ }^{13}$ are time consuming and the process is expensive and tedious. The present study describes a rapid and simple HPLC method for the determination of nicardipine hydrochloride in human plasma by using RP C-18 column.

\section{Experimental}

Nicardipine hydrochloride was obtained from M/s. ICN Biomedicals, USA. Nifedipine was a gift sample from M/s Torrent Laboratories, Ahmedabad, India. Potassium dihydrogen phosphate was of analytical grade and supplied by M/s. S.D Fine-Chem limited, Mumbai, India. Acetonitrile and water used were of HPLC grade (E-Merck). All other reagents used in the study were of AR quality (Qualigens). A commercial (M/s. Zenith Goldline Pharmaceuticals, USA) capsules dosage form containing $30 \mathrm{mg}$ of nicardipine hdrochloride was used in the study.

\section{Instrumentation}

A gradient HPLC (Shimadzu HPLC Class VP series) with two LC-10AT VP pumps, variable wave length programmable UV/VIS Detector SPD-10A VP, CTO-10AS VP Column oven (Shimadzu), SCL-10A VP system controller (Shimadzu), a disposable guard column LC-18 (Pelliguard ${ }^{\mathrm{TM}}$, LC-18, $2 \mathrm{~cm}$, Supelco, Inc., Bellefonte, PA.) and RP C-18 column (250 mm X $4.6 \mathrm{~mm}$ I.D., particle size $5 \mu \mathrm{m}$; YMC Inc., USA) was used. The HPLC system was equipped with the software "Class-VP series version 5.03 (Shimadzu)".

\section{HPLC conditions}

Both acetonitrile and $0.02 \mathrm{M}$ potasium dihydrogen phosphate solution were filtered before use through $0.45-\mu \mathrm{m}$ membrane filter, and were pumped from the respective solvent reservoirs in the ratio of $60: 40 \mathrm{v} / \mathrm{v}$ to the column at a flow rate of $1 \mathrm{~mL} / \mathrm{min}$ which yielded a column back-pressure of $74-75 \mathrm{~kg} / \mathrm{cm}^{2}$. The run time was set at $10 \mathrm{~min}$ and the column temperature was maintained at $40^{\circ} \mathrm{C}$. The volume of each injection was $20 \mu \mathrm{l}$. Prior to injecting solutions, the column was equilibrated for at least $30 \mathrm{~min}$ with the mobile phase flowing through the systems. The detector sensitivity was set at 0.0001 a.u.f.s and eluents were monitored at $239 \mathrm{~nm}$ and the data was acquired, stored and analyzed with the software "Class-VP series version 5.03 (Shimadzu)".

\section{Procedure}

Solutions were prepared on a weight basis and volumetric flasks were used to minimize solvent evaporation. The quantification of the drug was accomplished by an internal standard method. Stock solutions of nicardipine hydrochloride and nifedipine were prepared 
by dissolving $100 \mathrm{mg}$ of drug in $100 \mathrm{~mL}$ volumetric flask containing $70 \mathrm{~mL}$ of methanol, vortexed for about $15 \mathrm{~min}$ and then made up to volume with methanol. Daily working standard solutions of nicardipine hydrochloride was prepared by suitable dilution of the stock solution with mobile phase.

\section{Calibration solutions}

Five sets of plasma samples with varying drug concentrations were prepared by spiking drug-free plasma with an appropriate volume $(100 \mu \mathrm{L})$ of a known amount nicardipine hydrochloride at a concentration range of 2.5 to $150 \mathrm{ng} / 0.5 \mathrm{~mL}$ of plasma along with $100 \mu \mathrm{L}$ of $0.1 \mu \mathrm{g} / 0.5 \mathrm{~mL}$ of nifedipine (internal standard) solution.

\section{Plasma extraction procedure}

An aliquot of plasma $(0.5 \mathrm{~mL})$ was accurately measured into a $10-\mathrm{mL}$ glass tube with a teflonlined cap, followed by the addition of $100 \mu \mathrm{L}$ of $0.1 \mu \mathrm{g} / 0.5 \mathrm{~mL}$ of nifedipine solution as internal standard. To the above plasma samples $5 \mathrm{~mL}$ of ethyl acetate was added as extracting solvent, vortexed for $5 \mathrm{~min}$, centrifuged at 3,000 rpm for $10 \mathrm{~min}$, organic layer was separated and dried under vacuum evaporation. The residue was reconstituted with $0.1 \mathrm{~mL}$ of acetonitrile. Twenty microliters of the resultant solution was injected into the column (RP-C18).

\section{Accuracy and precision}

Aliquots of blank plasma $(0.5 \mathrm{~mL})$ were spiked with fixed quantity of internal standard $(0.1 \mu \mathrm{g} / 0.5 \mathrm{~mL})$ and of nicardipine hydrochloride solutions $(100 \mu \mathrm{L})$ with various strengths to yield concentrations of 5,20,50,100 and $150 \mathrm{ng}$. Each of these samples was extracted as described above and the resulting reconstituted solutions were injected into the HPLC column $(n=5)$. Each sample was prepared in five sets on three consecutive days and were assayed by the proposed HPLC method to find the precision and accuracy of the method. Accuracy was expressed as the mean percentage error [(mean measured concentration)/(expected concentration)] X 100. Precision was calculated as intra- and interday coefficient of variation $(\mathrm{CV})[\% \mathrm{C} . \mathrm{V}=(\mathrm{SD} / \mathrm{mean}) \mathrm{X} 100]$. Least square regression method was used to determine the regression equation and correlation coefficient.

\section{Results and Discussion}

Nicardipine hydrochloride and nifedipine appeared on the chromatograph in approximately 6.490 and 4.978 min respectively with no interfering peaks (Figure 1). The run time of the method was set at 10 minutes. When the same drug solution was injected 5 times, the retention time of both the drug and internal standard were same. This indicates that the proposed HPLC method is rapid, which in turn shows that the method consumes lesser amounts of expensive HPLC solvents. Table 1 shows the mean peak area ratios of nicardipine hydrochloride to nifedipine (internal standard) solutions for 5 such determinations. When the concentration of nicardipine hydrochloride and its respective peak area ratios (peak area nicardipine hydrochloride/ peak area of nifedipine) were subjected to regression analysis by least squares method, a high correlation coefficient was observed $(\mathrm{r}=0.9987)$ in the range of 5 to $150 \mathrm{ng} / 0.5 \mathrm{~mL}$. However, the lower detection limit was found to be $2.5 \mathrm{ng} / 0.5 \mathrm{~mL}$ of human plasma. The regression of nicardipine hydrochloride concentration over its peak area ratio was found to be $Y=0.02864+0.01161 \mathrm{X}$ where ' $\mathrm{Y}$ ' is the peak area ratio and ' $\mathrm{X}$ ' is the concentration of nicardipine hydrochloride in human plasma. This regression equation is used to estimate the amount of nicardipine hydrochloride in plasma or in validation study (precision and accuracy). 
When the proposed HPLC method was validated for intra- and inter-day variation, it showed less than $2.5 \%$ of CV (Table 2). To assess the assay recovery from plasma after extraction with ethyl acetate, known quantity of the drug $(10,20,50$ or 100ng) along with internal standard was added to drug-free plasma and the resulting reconstituted solutions were repeatedly injected on the same day. The coefficient of variation $(\mathrm{CV})$ in the peak area ratio for five replicate injections was found to be less than $3.5 \%$ and there was a high recovery (Table 3 ) of the drug $(95.04 \pm 3.09 \%)$. Thus, the results show that the proposed HPLC method is highly reproducible and accurate.

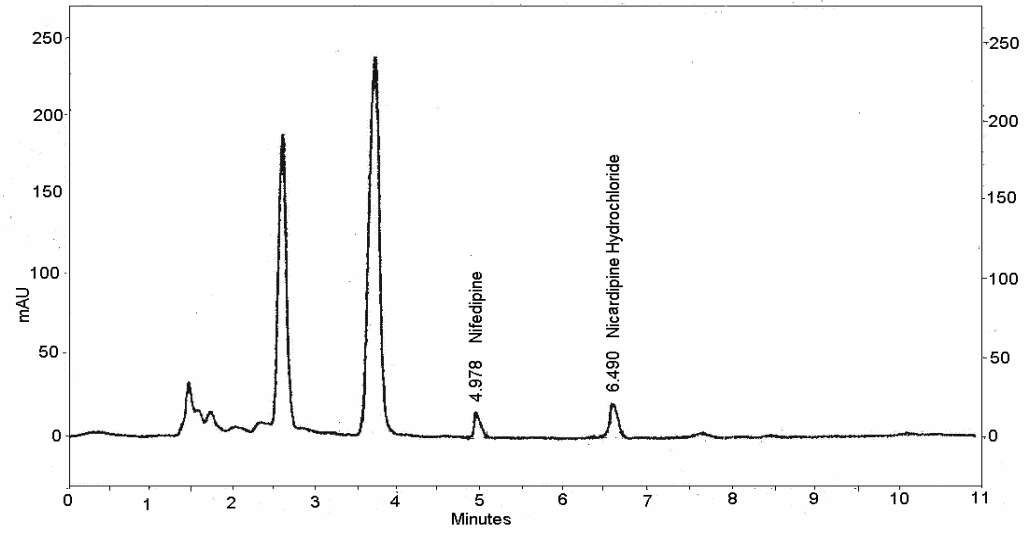

Figure 1

Table 1. Calibration and precision of the HPLC assay

\begin{tabular}{ccc}
\hline $\begin{array}{c}\text { Amount of nicardipine hydrochloride added to } 0.5 \mathrm{~mL} \\
\text { of human plasma (ng) }\end{array}$ & Peak-area ratio* & $\%$ C.V. \\
\hline 0 & 0 & 0 \\
5 & 0.06182 & 1.06 \\
10 & 0.15048 & 1.64 \\
20 & 0.29358 & 0.56 \\
50 & 0.62888 & 1.65 \\
100 & 1.20797 & 2.01 \\
150 & 1.74818 & 0.98 \\
\hline
\end{tabular}

*: Mean of five determinations Regression Equation: $\mathrm{Y}=0.02864+0.01161 \mathrm{X}(\mathrm{r}=0.9987)$

Table 2. Inter- and intra-day precision for nicardipine hydrochloride assay in human plasma of the proposed HPLC method

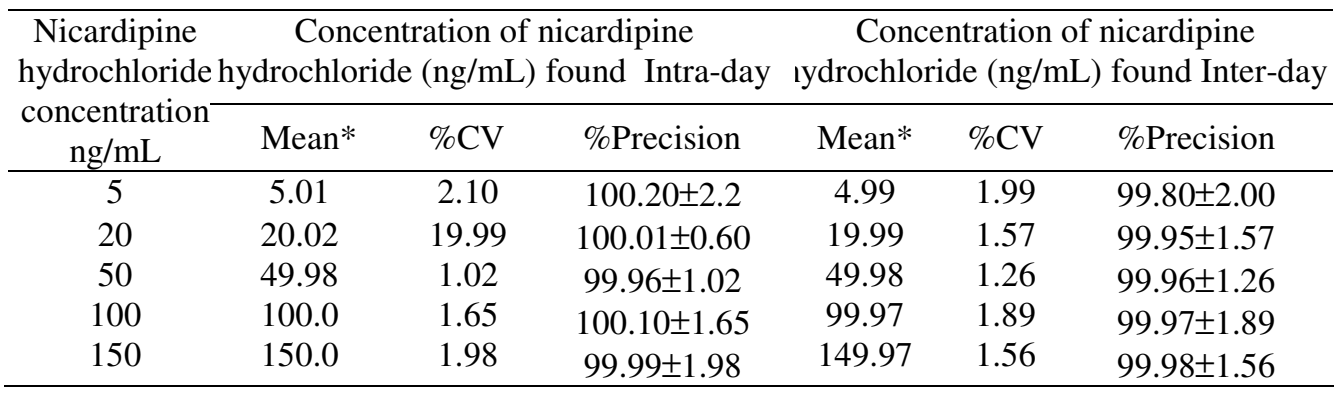

*: Mean of five determinations 
Table 3. Experimental values obtained in the recovery of Nicardipine hydrochloride from plasma

\begin{tabular}{cccc}
\hline \multicolumn{3}{c}{ Amount of standard drug, $\mathrm{ng}$} & \multirow{2}{*}{ \% Recovery } \\
\cline { 1 - 3 } Added & Recovered* $^{*}$ & \%CV & \\
\hline 10 & $8.96 \pm 0.26$ & 2.9 & $89.6 \pm 2.60$ \\
20 & $17.72 \pm 0.68$ & 3.8 & $88.60 \pm 3.4$ \\
50 & $43.25 \pm 1.51$ & 3.49 & $86.60 \pm 3.62$ \\
100 & $95.04 \pm 2.69$ & 2.83 & $95.04 \pm 3.09$ \\
\hline \multicolumn{4}{c}{ *ean of five determinations }
\end{tabular}

In order to find the utility of this HPLC method for the estimation of nicardipine hydrochloride in plasma in need-based situations, an immediate release capsule dosage form (dose $30 \mathrm{mg}$ ) was administered to six volunteers. The plasma concentration of the drug was estimated by the proposed HPLC method. There was no interference of any other plasma component with the drug and internal standard peaks. The plasma concentration of nicardipine hydrochloride in plasma samples is shown in Table 4. The sensitivity of the assay is sufficient for the determination of nicardipine hydrochloride in human plasma at 0.5 $\mathrm{h}$ and $12 \mathrm{~h}$ after administration of an immediate release capsule. The results of the study show that the proposed HPLC method is simple, rapid, sensitive, precise and accurate for the estimation of nicardipine hydrochloride in human plasma and could be used for biopharmaceutical and pharmacokinetic evaluation of drug and its formulations.

\section{Acknowledgements}

The authors acknowledge the financial support received from Government of India, Department of Science and Technology (DST) and All India Council for Technical Education (under MODROBS) in establishing the infrastructure for HPLC. The authors greatly acknowledge M/s Torrent Laboratories, Ahmedabad, India, for providing the gift sample of nifedipine.

\section{References}

1. Graham D J M, Dow R J, Hall D J, Alexander O F, Mroszczat E J and Freedman D, Brit. J Clin Pharmacol, 1985, 20, 235.

2. Dow R J and Graham D J M, Brit J Clin Pharmacol, 1986, 22, 1955.

3. Li K, Zhang X, Yuan Y S and Zhao F L, Biome. Chromatogr, 1998, 12, 326.

4. Meng Q C, Cheung A T, Guvakov D, Weiss S J, Savino J S, Salgo I S and Marshall B E, J Chromatogr B Biomed Sci, 1998,23, 718.

5. Eastwood R J, Galustian C, Bhamra R K and Holt D W, J Chromatogr, 1990, 530, 463.

6. Greiner P O, Angignard D and Cahn J, J Pharm Sci, 1988, 77, 387.

7. Kobayashi S S, J Chromatogr, 1987, 420, 439.

8. Telting-Diaz M, Kelly M T, Hua C and Smyth M R, J Pharm Biome Anal 1991,9,889.

9. Visor G C, Bajka E and Benjamin E, J Pharm Sci, 1986, 75, 44.

10. Imai K, Higashidate S, Prados P R, Santa T, Adachi-Akahane S and Nagao T, Bio. Pharm. Bull, 1994, 17, 907.

11. Uno T, Ohkubo T and Sugawara K, J Chromatogr B Biome. Sci Appl, 1997, 698, 181.

12. Iwaoka $\mathrm{T}$, Inotsume $\mathrm{N}$, Inoue J, Naomi S, Okamoto $\mathrm{Y}$, Higuchi $\mathrm{S}$, Nakano $\mathrm{M}$ and Umeda T, Eur J Clin Pharmacol, 1995, 48, 345.

13. Inotsume N, Iwaoka T, Honda M, Nakano M, Okamoto Y, Naomi S, Tomita K, Teramura T and Higuchi S, Eur J Clin Pharmacol, 1997,52, 289. 


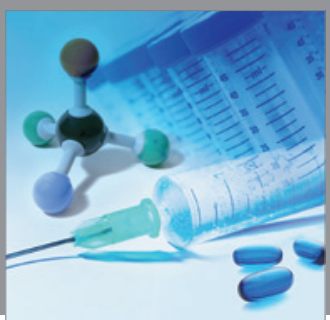

International Journal of

Medicinal Chemistry

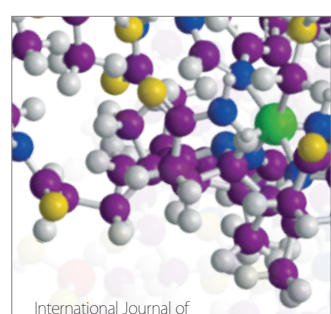

Carbohydrate Chemistry

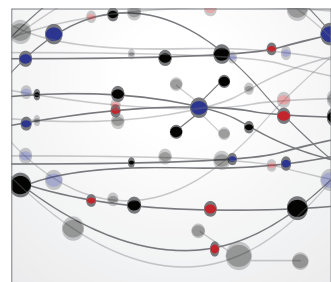

The Scientific World Journal
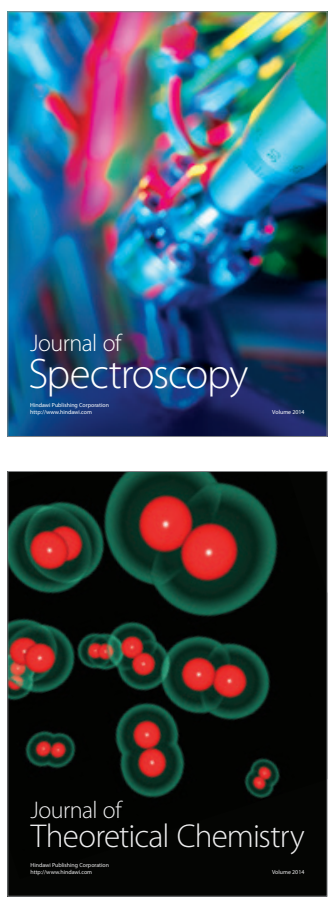
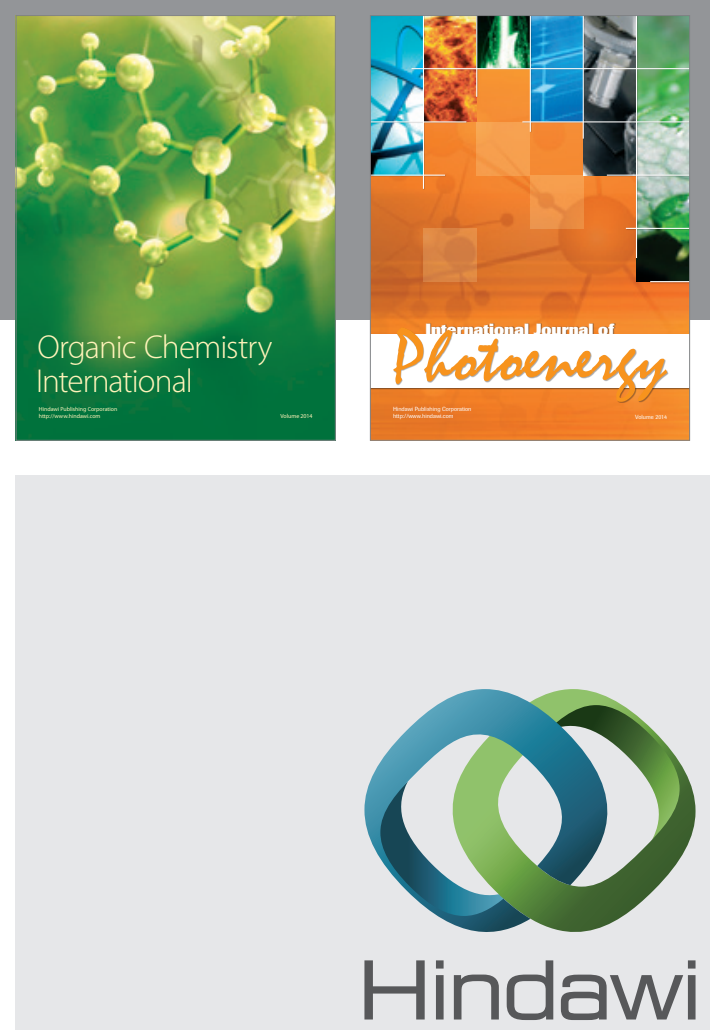

Submit your manuscripts at

http://www.hindawi.com
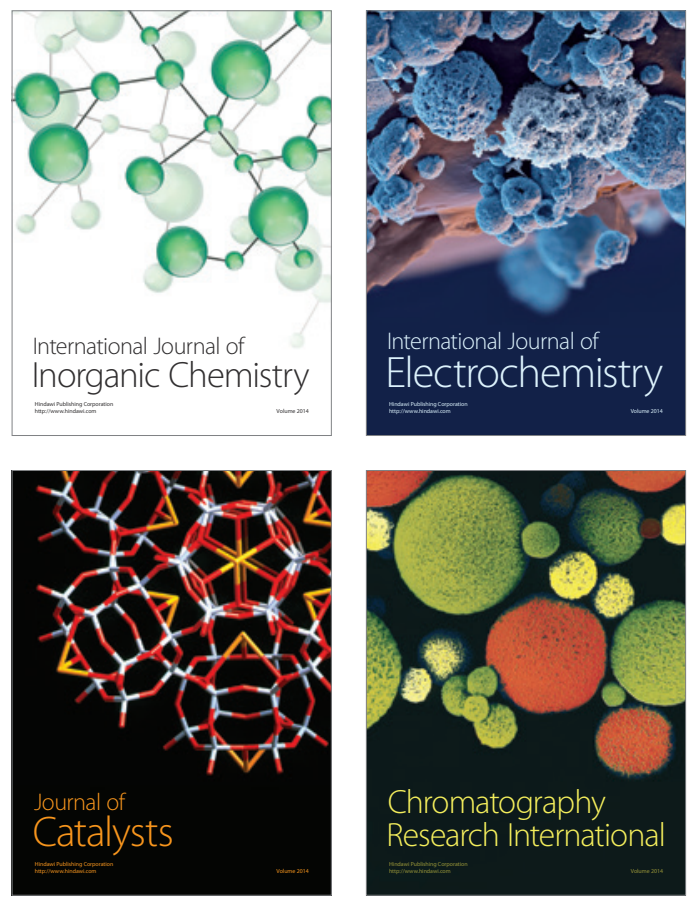
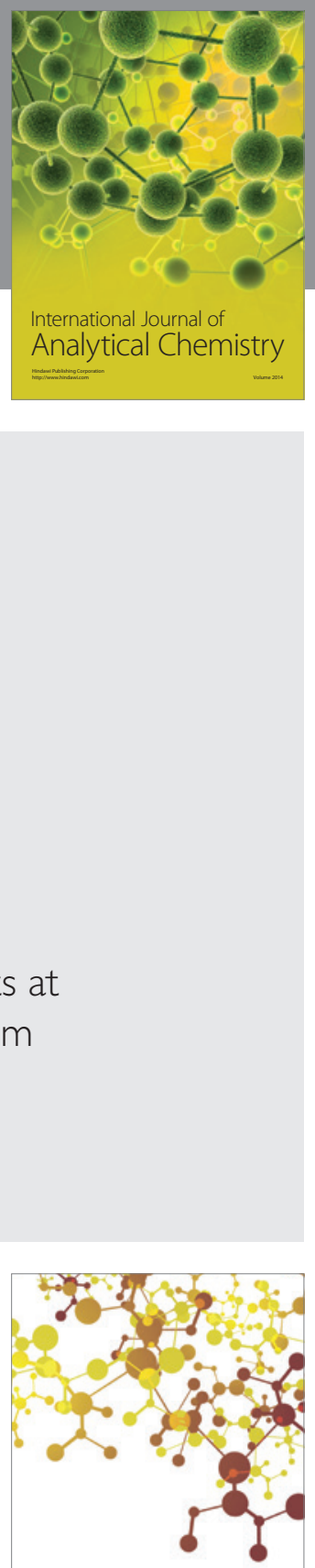

Journal of

Applied Chemistry
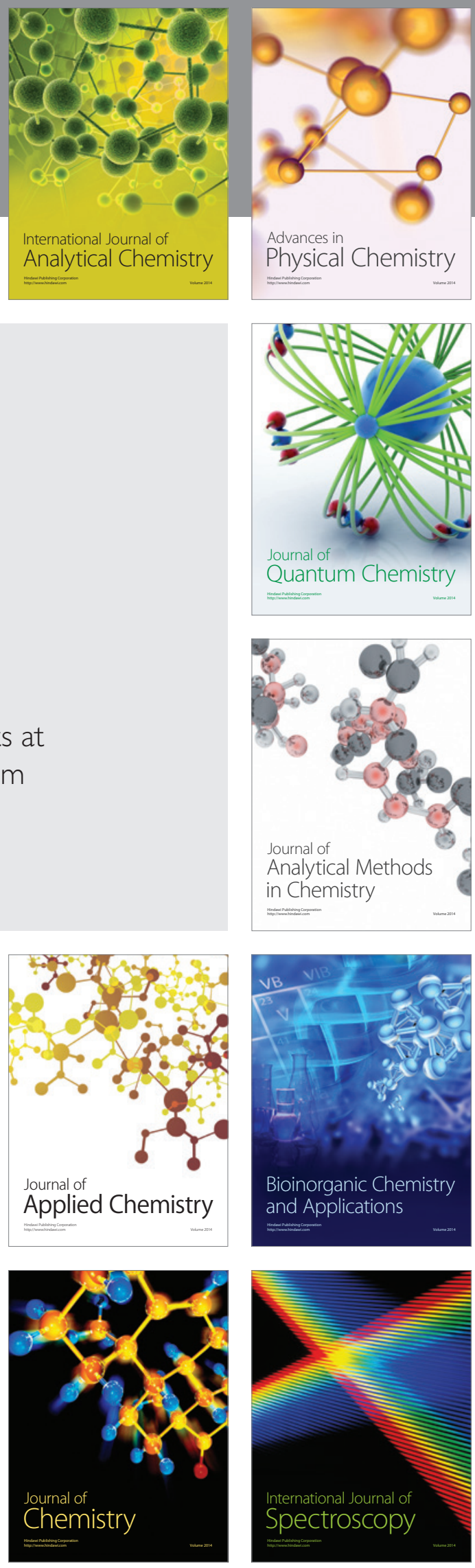